\title{
A new luminescent silver-based probe for on/off sulfide determination
}

\author{
Daniel Fonseca Segura $^{\text {a,b,* }}$, João Flávio da Silveira Petruci ${ }^{\text {a,*** }}$, Arnaldo Alves Cardoso a \\ Regina Célia Galvão Frem ${ }^{\text {a }}$, Adelino Vieirade de Godoy Netto ${ }^{a}$, Neil R. Champness ${ }^{b}$ \\ a Institute of Chemistry, UNESP - Universidade Estadual Paulista, Araraquara, São Paulo, Brazil \\ b School of Chemistry, University of Nottingham, Nottingham, United Kingdom
}

\section{A R T I C L E I N F O}

Article history:

Received 17 July 2015

Received in revised form 21 October 2015

Accepted 29 November 2015

Available online 1 December 2015

\section{Keywords:}

Luminescent probes

Silver complex

Sulfide detection

\begin{abstract}
A B S T R A C T
The sulfide anion is a corrosive, toxic and harmful compound found in a wide range of anoxic environments. Metal-based complexes have been used as luminescent probes for sulfide determination. However, their synthesis usually involves laborious procedures and the use of toxic reagents. In this paper, we describe the synthesis, characterization and application of a new, sensitive and selective silver complex probe for sulfide detection. The process of sulfide determination is based on rapid reaction in aqueous/methanolic media between the silver (I) complex and sulfide leading to an increase in fluorescence intensity. Analytical performance has been studied in the concentration range of 190 to $950 \mathrm{nmol} \mathrm{L}^{-1}$ of sulfide with suitable linearity, and the limit of detection was calculated to be $(3 \sigma / \mathrm{S})$ to $20 \mathrm{nmol} \mathrm{L}^{-1}$. The probe's selectivity to $\mathrm{S}^{2-}$ was evaluated over other competing anions showing excellent results and its reversibility was demonstrated upon addition of $\mathrm{AgCF}_{3} \mathrm{SO}_{3}$.
\end{abstract}

(c) 2015 Elsevier B.V. All rights reserved.
Sulfides have been found in anoxic environments including natural water, wastewater, crude petroleum, natural gas and volcanic gases [1]. Water containing sulfide does not usually pose a health risk, but it can give water an unpleasant "rotten egg" smell and taste [2]. Determination of sulfide concentration is an important parameter to guarantee drinking water quality. Controlling sulfides is an important issue in wastewater since sulfide solutions can attack metals, concrete and cause corrosion on pipe walls, resulting in significant economic damage. In the human body, mercaptans are readily oxidized to their respective sulfides and, consequently, sulfide can be founded in animal halite. Animals showing signs of liver cirrhosis produce more sulfides in their bloodstream and halite. Thus, determination of sulfide could be used as a marker of liver diseases [3].

Environmental sulfide concentration has been usually found in concentrations of $\mu \mathrm{mol} \mathrm{L}{ }^{-1}$. For example, the recognition threshold range which hydrogen sulfide odor can be detected by humans is $0.30-90 \mu \mathrm{mol} \mathrm{L}^{-1}$ [4]. Thus, the determination of sulfide is essential in a variety of different human activities, but continues to present challenges due to the complexity of samples, and the necessity to determine low concentrations of sulfide.

\footnotetext{
* Correspondence to: D.F. Segura, Depto de Química Geral e Inorgânica, Instituto de Química, UNESP, Rua Francisco Degni 55, Araraquara, São Paulo ZIP 14801-970, Brazil. ** Correspondence to: J. F. S. Petruci, Depto de Química Analitica, Instituto de Química, UNESP, Rua Francisco Degni 55, Araraquara, São Paulo ZIP 14801-970, Brazil.

E-mail addresses: danielfsegura@outlook.com (D.F. Segura), jfpetruci@gmail.com (J.F.S. Petruci).
}

Fluorescence is an appealing technique for determination of sulfide because of its high sensitivity and potential for selectivity. Indeed, molecular fluorescent probes can offer high sensitivity, real-time imaging, high spatiotemporal resolution and have excellent potential as useful tools [5-9].

Luminescent metal-based complexes have previously been described as sulfide recognition and determination probes [10-15]. Mercury-complexing agents, such as alkaline fluorescein mercuric acetate (FMA), have mainly been employed to sulfhydryl group determination [10]. This well-known and sensitive reaction results in quenching of FMA fluorescence. However, the drawback of this reaction is the use of a toxic metal which generates residues which require expensive disposal procedures. Zinc, ruthenium, copper and palladium have also been used as luminescent probes, but usually involve laborious and time-consuming synthesis, high cost, and often a low yield of the desired product. Environmentally friendly metals with high affinity to sulfides could be a promising alternative research path. $\mathrm{Ag}$ (I) ions rapidly react with sulfide forming a slightly water soluble compound $\left(\mathrm{Ksp}=1.48 \times 10^{-51}\right)[16]$, and has been used in several analytical methods for sulfide determination [17] but has not been exploited previously as a luminescent metal-based probe. Herein we describe, for the first time, the synthesis of the new silver(I) complex bearing 1,10phenanthroline-5,6-[pteridine-2,4-diamine] (phenpte), and its use as a sensitive on/off luminescent probe for sulfide determination.

The silver (I) complex was prepared by a two step route. Firstly, ligand 1,10-phenanthroline-5,6-[pteridine-2,4-diamine] (phenpte) was synthesized by the reaction of a 1:1 mixture of 1,10- 
I)<smiles>O=C1C(=O)c2cccnc2-c2ncccc21</smiles>

II)<smiles>Nc1nc(N)c2nc3c4cccnc4c4ncccc4c3nc2[nH+]1</smiles>

phenpte<smiles>Nc1nc(N)c(N)c(N)n1</smiles>

\section{$\mathrm{AgCF}_{3} \mathrm{SO}_{3}$}

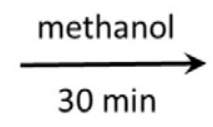

Fig. 1. Synthesis scheme of 1,10-phenanthroline-5,6-[pteridine-2,4-diamine] (phenpte) and the new silver(I) $\operatorname{complex}[\mathrm{Ag}(\mathrm{phenpte})] \mathrm{CF}_{3} \mathrm{SO}{ }_{3}$.

phenanthroline-5,6-dione and 2,4,5,6-tetraminepyrimidine in refluxing methanol for $2 \mathrm{~h}[18,19]$. Subsequently, separate methanol solutions of phenpte and $\mathrm{AgCF}_{3} \mathrm{SO}_{3}$ (1:1 ratio) were mixed with stirring and exclusion of ambient light. After $30 \mathrm{~min}$ a yellow precipitate had formed, was filtered, washed with cold methanol, chloroform, diethyl ether, and dried in a vacuum. Elemental $(\mathrm{C}, \mathrm{H}, \mathrm{N})$ analysis results indicate formation of the complex $[\mathrm{Ag}$ (phenpte) $] \mathrm{CF}_{3} \mathrm{SO}_{3}$ as the product. Spectroscopic data indicates that the phenpte ligand coordinates in two different modes, the phenanthroline moiety chelates to the silver ion as a bidentate ligand and the amino group coordinates to a different silver ion as a monodentate ligand [21]. Fig. 1 shows the synthesis of phenpte (I) and $[\mathrm{Ag}$ (phenpte) $] \mathrm{CF}_{3} \mathrm{SO}_{3}$ (II), and suggests a possible extended structure of $[\mathrm{Ag}$ (phenpte) $] \mathrm{CF}_{3} \mathrm{SO}_{3}$ as a coordination polymer.

Preliminary luminescent studies of phenpte, in methanol, show a strong emission peak centered at $492 \mathrm{~nm}$ when the ligand is excited at $376 \mathrm{~nm}$. Upon addition of $\mathrm{AgCF}_{3} \mathrm{SO}_{3}$, ligand fluorescence is strongly quenched as shown in Fig. 2. Moreover, phenpte luminescence is suppressed when an equivalent of $\mathrm{Ag}(\mathrm{I})$ is added to a solution of phenpte, corroborating the proposed 1:1 metal-ligand stoichiometry. Importantly the addition of metal ions such as $\mathrm{Pb}^{2+}, \mathrm{Al}^{3+}, \mathrm{Fe}^{3+}, \mathrm{Cd}^{2+}, \mathrm{Ni}^{2+}$ and $\mathrm{Pd}^{2+}(1: 1$ ratio $)$ had no significant effect on phenpte fluorescence intensity. However, the addition of $\mathrm{Cu}^{+}$ and $\mathrm{Cu}^{2+}$ showed similar effects to $\mathrm{Ag}^{+}$on phenpte luminescence (Table 1).

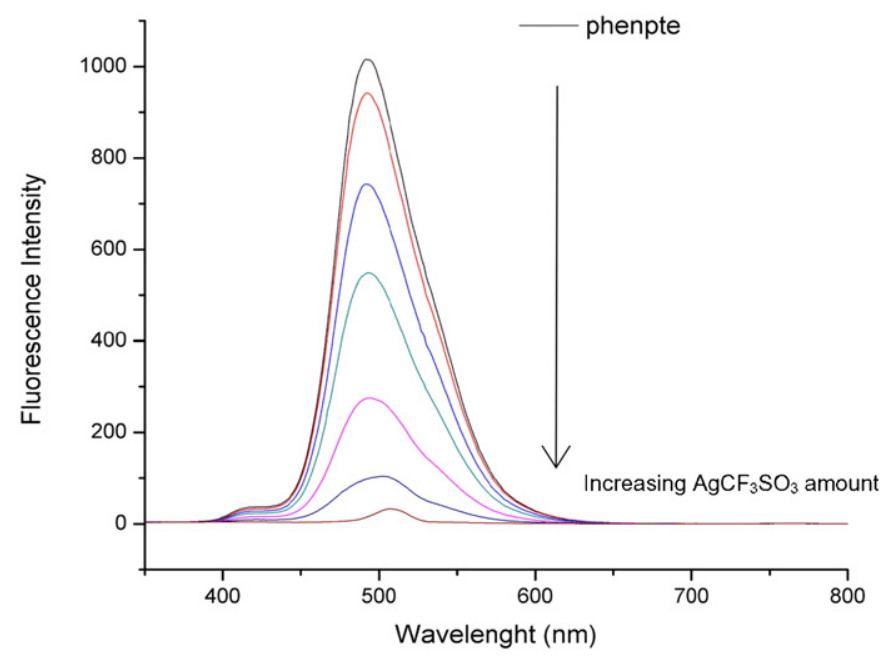

Fig. 2. Effect on intensity of phenpte fluorescence upon the addition of $\mathrm{AgCF}_{3} \mathrm{SO}_{3}$. Concentration of $\mathrm{AgCF}_{3} \mathrm{SO}_{3}$ solution: $0.2 \mathrm{mmol} \mathrm{L}^{-1}$. Volume of $\mathrm{AgCF}_{3} \mathrm{SO}_{3}$ added: 10, 20, 30, 40, 60 and $80 \mu \mathrm{L}$.
Upon addition of sulfide [20], the quenching effect (sensor mode off) of the $\mathrm{Ag}(\mathrm{I})$ cation is reduced by strong interaction between $\mathrm{Ag}(\mathrm{I})$ and $\mathrm{S}^{2-}\left(\mathrm{Ksp}=1.48 \times 10^{-51}[16]\right)$, forming $\mathrm{Ag}_{2} \mathrm{~S}$ and leading to the liberation of the free ligand. As a result, an increase of fluorescence intensity (sensor mode on) has been observed (see Fig. 3), and reached a plateau in less than $2 \mathrm{~min}$, after which no further increase was observed (up to at least $2 \mathrm{~h}$ ).

Among common potential interfering species, anions such as $\mathrm{NO}_{3}^{-}, \mathrm{NO}_{2}^{-}, \mathrm{SCN}^{-}, \mathrm{SO}_{4}^{--}, \mathrm{Cl}^{-}$and $\mathrm{CO}_{3}^{2-}$ were evaluated and did not increase fluorescence intensity (Table 2). Hence, excellent sulfide recognition has been demonstrated for this new silver (I) complex.

Reversibility is a fundamental issue in probe design. The reversibility of the $[\mathrm{Ag}$ (phenpte) $] \mathrm{CF}_{3} \mathrm{SO}_{3}$ probe in methanolic solution was evaluated by adding a further equivalent of $\mathrm{AgCF}_{3} \mathrm{SO}_{3}$, in methanol solution, following previous reaction between $[\mathrm{Ag}$ (phenpte) $] \mathrm{CF}_{3} \mathrm{SO}_{3}$ and sulfide. The fluorescence signal shows a reversible cycle upon alternating addition of sulfide and $\mathrm{Ag}(\mathrm{I})$ ions. Fig. 4 shows that fluorescence intensity versus time (seconds) demonstrates the return of the fluorescence signal to original values upon the addition of $\mathrm{AgCF}_{3} \mathrm{SO}_{3}$, confirming the ability to rejuvenate the probe complex, $[\mathrm{Ag}$ (phenpte) $] \mathrm{CF}_{3} \mathrm{SO}_{3}$.

Furthermore, an analytical curve of fluorescence intensity $\left(\lambda_{\text {exc }}=\right.$ $376 \mathrm{~nm}, \lambda_{\text {em }}=492 \mathrm{~nm}$ ) versus sulfide concentration has been established for quantitative data evaluation. For each concentration, measurements were performed in triplicate over a range of 0.19 to $0.95 \mu \mathrm{mol} \mathrm{L}{ }^{-1}$. The curve linearity was evaluated over the same concentration range, with a linearity factor of $r>0.99$. The probe's limit of detection (LD) has been determined as $0.02 \mu \mathrm{mol} \mathrm{L}{ }^{-1}$. Repeatability was evaluated by measuring the fluorescence intensity of ten repeat additions of $0.50 \mu \mathrm{mol} \mathrm{L}{ }^{-1}$ of sulfide, achieving excellent results (4\% R.S.D).

In conclusion, a new on/off luminescent probe has been developed for sulfide determination. The new probe is based on a

Table 1

Effect of addition of one equivalent of metal cations on phenpte fluorescence intensity comparing to $\mathrm{Ag}^{+}$(factor of 1.00).

\begin{tabular}{ll}
\hline Metal & Effect factor \\
\hline $\mathrm{Ag}^{+}$ & 1.00 \\
$\mathrm{Al}^{3+}$ & 0.02 \\
$\mathrm{Cd}^{2+}$ & 0.04 \\
$\mathrm{Fe}^{3+}$ & 0.02 \\
$\mathrm{Ni}^{2+}$ & 0.02 \\
$\mathrm{~Pb}^{2+}$ & 0.02 \\
$\mathrm{Cu}^{+}$ & 0.70 \\
$\mathrm{Cu}^{2+}$ & 0.90
\end{tabular}




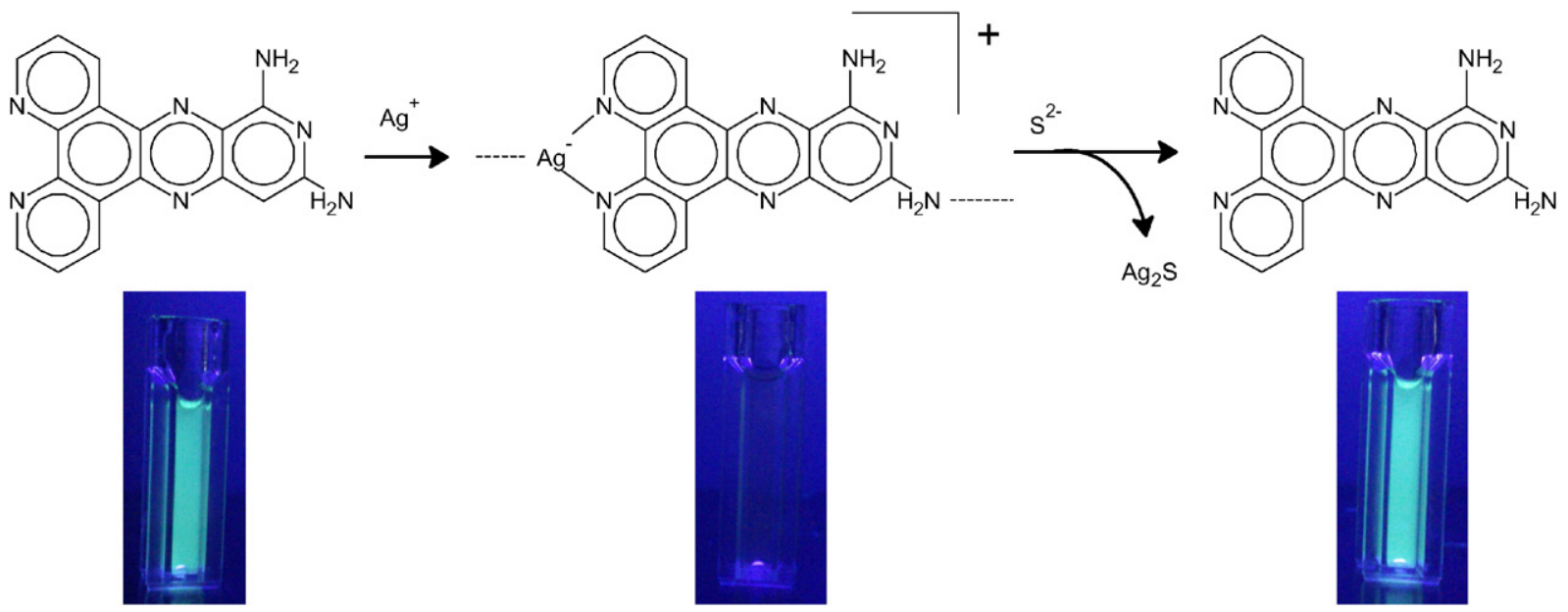

Fig. 3. Luminescence response mechanism of $[\mathrm{Ag}$ (phenpte) $] \mathrm{CF}_{3} \mathrm{SO}_{3}$ towards $\mathrm{H}_{2} \mathrm{~S}$.

Table 2

Effect of interfering ions upon sulfide determination. In each instance a ratio of 100:1 of interferent sulfide was used.

\begin{tabular}{llc}
\hline Interferent & [ion]/[sulfide] & Interference \\
\hline $\mathrm{NO}_{3}^{-}$ & 100 & $-1.7 \%$ \\
$\mathrm{NO}_{2}^{-}$ & 100 & $-2.7 \%$ \\
$\mathrm{SCN}^{-}$ & 100 & $-3.6 \%$ \\
$\mathrm{SO}_{4}^{2-}$ & 100 & $-1.9 \%$ \\
$\mathrm{Cl}^{-}$ & 100 & $3.6 \%$ \\
$\mathrm{CO}_{3}^{2-}$ & 100 & $1.4 \%$ \\
\hline
\end{tabular}

silver complex synthesized by mixing a luminescent dye $(1,10$ phenanthroline-5,6-[pteridine-2,4-diamine]) and $\mathrm{AgCF}_{3} \mathrm{SO}_{3}$. The probe fluorescence intensity increases proportionally upon sulfide addition. Analytical performance of the probe shows excellent results competitive with other probes in the literature $[10,13,19]$. Moreover, the use of a non-toxic metal, ease of preparation and reversibility of the probe represent a valuable contribution in

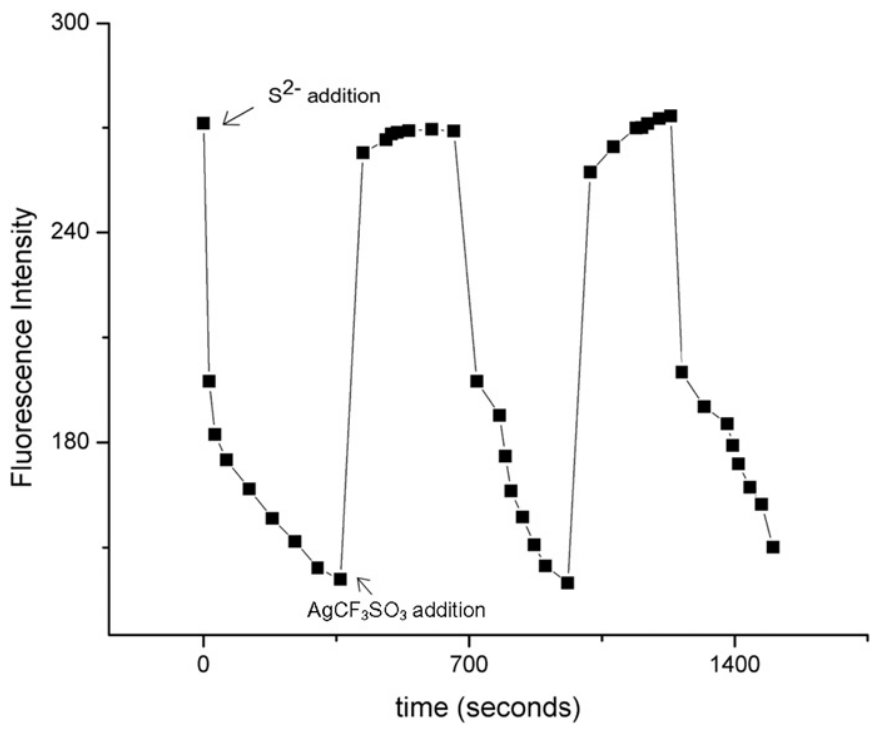

Fig. 4. Test for sensing capabilities of $[\mathrm{Ag}$ (phenpte) $] \mathrm{CF}_{3} \mathrm{SO}_{3}$ complex. Variation of the fluorescence signal intensity at $492 \mathrm{~nm}$, alternating additions of sulfide ions (signal intensity increases) and $\mathrm{Ag}^{+}$ions (signal intensity decreases). Experimental conditions: Concentration and volume of the complex solution: $0.1 \mathrm{mmol} \mathrm{L}^{-1}$ and $3.0 \mathrm{~mL}$; concentration and volume of sulfide solution added: $10 \mu \mathrm{mol} \mathrm{L}^{-1}$ and $10 \mu \mathrm{L}$; concentration and volume of $\mathrm{AgCF}_{3} \mathrm{SO}_{3}$ added: $0.2 \mathrm{mmol} \mathrm{L}^{-1}$ and $15 \mu \mathrm{L}$. the development of metal-based luminescent probes for sulfide determination.

\section{Acknowledgments}

This research was supported by CNPq (487092/2012-0), FAPESP (2013/22995-4) and CAPES (12707/12-0). NRC gratefully acknowledges receipt of a Royal Society Wolfson Merit Award.

\section{Appendix A. Supplementary material}

Supplementary data to this article can be found online at http://dx. doi.org/10.1016/j.inoche.2015.11.019.

\section{References}

[1] N.S. Lawrence, J. Davis, R.G. Compton, Talanta 52 (2000) 771-784.

[2] M.E.A.G. Oprime, O. Garcia, A.A. Cardoso, Process Biochem. 37 (2001) 111-114.

[3] N. Marczin, M. Yacoub, Disease Markers in Exhaled Breath: Basic Mechanisms and Clinical Applications, 2002.

[4] T.L. Guidotti, Int. J. Toxicol. 29 (2010) 569-581.

[5] Z. Xu, J. Yoon, D.R. Spring, Chem. Soc. Rev. 39 (2010) 1996-2006.

[6] T. Ueno, T. Nagano, Nat. Methods 8 (2011) 642-645.

[7] N. Kumar, V. Bhalla, M. Kumar, Coord. Chem. Rev. 257 (2013) 2335-2347.

[8] V.S. Lin, C.J. Chang, Curr. Opin. Chem. Biol. 16 (2012) 595-601.

[9] A. Cardoso, H. Liu, P. Dasgupta, Talanta 44 (1997) 1099-1106.

[10] H.D. Axelrod, J.H. Cary, J.E. Bonelli, J.P. Lodge, Anal. Chem. 41 (1969) 1856-1858.

[11] E. Galardon, A. Tomas, P. Roussel, I. Artaud, Dalton Trans. (2009) 9126-9130.

[12] R. Zhang, X. Yu, Y. Yin, Z. Ye, G. Wang, J. Yuan, Anal. Chim. Acta 691 (2011) 83-88.

[13] J.F.D.S. Petruci, A.A. Cardoso, Microchem. J. 106 (2013) 368-372.

[14] X. Lou, H. Mu, R. Gong, E. Fu, J. Qin, Z. Li, Analyst 136 (2011) 684-687.

[15] L. Tang, P. Zhou, Q. Zhang, Z. Huang, J. Zhao, M. Cai, Inorg. Chem. Commun. 36 (2013) 100-104.

[16] T.-M. Hseu, G.A. Rechnitz, Anal. Chem. 40 (1968) 1054-1060.

[17] R. Chen, H.R. Morris, P.M. Whitmore, Sensors Actuators B Chem. 186 (2013) 431-438.

[18] M.D. Stephenson, T.J. Prior, M.J. Hardie, Cryst. Growth Des. 8 (2008) 643-653.

[19] S.R. Dalton, S. Glazier, B. Leung, S. Win, C. Megatulski, S.J.N. Burgmayer, J. Biol. Inorg. Chem. 13 (2008) 1133-1148.

[20] A.D. Eaton, M.A.H. Franson, A.P.H. Association, A.W.W. Association, W.E. Federation, Standard Methods for the Examination of Water \& Wastewater, American Public Health Association, 2005.

[21] D.F. Segura, A.V.G. Netto, R.C.G. Frem, A.E. Mauro, P.B. da Silva, J.A. Fernandes, F.A.A Paz, A.L.T. Dias, N.C. Silva, E.T. de Almeida, M.J. Marques, L. de Almeida, K.F. Alves, F.R. Pavan, P.C. de Souza, H.B. de Barros, C.Q.F. Leite, Polyhedron 79 (2014) 197-206. 